\title{
CARACTERIZAÇÃO FISICO-QUÍMICA DE POLPA DE UMBU-CAJÁ EM PÓ OBTIDO PELO MÉTODO DE SECAGEM EM LEITO DE JORRO
}

\author{
P. C. FERREIRA ${ }^{1}$, J. P. COSTA ${ }^{2}$, D.M. LIMA ${ }^{1}$ e J. M. C. $\operatorname{COSTA}^{3}$ \\ ${ }^{1}$ Universidade Federal do Ceará, Graduando em Engenharia de Alimentos \\ ${ }^{2}$ Universidade Federal do Ceará, Departamento de Engenharia de Alimentos \\ ${ }^{3}$ Universidade Federal do Ceará, Departamento de Engenharia de Alimentos
}

E-mail para contato: priscilacosta784@ hotmail.com

\begin{abstract}
RESUMO - O umbu-cajá é um fruto tropical exótico do nordeste brasileiro que apresenta grandes possibilidades de crescimento no mercado interno devido às suas excelentes características organolépticas, qualidade nutricional e valor comercial. Entretanto, trata-se de um fruto perecível, apresentando altas taxas de perdas pós-colheita. Nesse contexto, faz-se necessário o uso de técnicas para a manutenção da qualidade pós-colheita das frutas. O processo de secagem em Leito de Jorro é uma alternativa viável de conservação para indústria de alimentos, pois possibilita a obtenção de um produto com qualidade e de maior vida útil. São objetivos deste trabalho a utilização do processo de secagem em leito de jorro utilizando como coadjuvante de secagem a maltodextrina em diferentes concentrações. Caracterização dos parâmetros físicos e físico-químicos do da polpa de umbu-cajá em pó. A partir dos resultados, observou-se que após o processo de secagem houve uma redução no teor de umidade e $\mathrm{a}_{\mathrm{w}}$, manutenção do $\mathrm{pH}$ baixo e um aumento no teor de sólidos solúveis totais, fatores importantes para a obtenção de um produto de qualidade, conservação das características nutricionais e aumento da vida útil do produto.
\end{abstract}

\section{INTRODUÇÃO}

A umbu-cajazeira é uma planta arbórea, pertencente à família Anacardiaceae, considerada um híbrido natural entre o umbuzeiro (Spondias tuberosa Arruda) e a cajazeira (Spondias mombin L.), (GIACOMETTI, 1993) e tem origem desconhecida, apresentando características de planta xerófila encontrada em plantios desorganizados, disseminados em Estados do Nordeste. O fruto do umbu-cajá tem posição de destaque devido às suas características organolépticas serem agradáveis. O processamento dessa fruta apresenta-se como uma forma viável de conservação, trazendo como vantagem a possibilidade de aproveitamento dos excedentes de produção, contornando problemas de sazonalidade e possibilitando sua distribuição por maiores períodos do ano (VIANA, 2008). Dessa forma, é indispensável à aplicação de técnicas de conservação, como a secagem, com o intuito de prolongar a vida útil desse produto, de reduzir custos de embalagem, armazenamento e 
transporte, e de facilitar sua manipulação e distribuição (GOULA e ADAMOPOULOS, 2010). A desidratação de polpas de frutas tem como objetivos: diminuir o teor de água, atividade de água e prolongar a vida de prateleira do produto. É um dos métodos mais aplicados na conservação dos alimentos em função de evitar a deterioração e perda do valor comercial dos mesmos (SOARES, 2001). A secagem em leito de jorro produz sucos em pó com boa estabilidade microbiológica, uma vez que esses secadores estão entre os sistemas mais utilizados para a secagem de sólidos, suspensões, polpas e pastas, principalmente devido às vantagens de altas taxas de transferência de calor e de massa entre os sólidos e o ar, resultando em baixos tempos de secagem (CABRAL et al., 2007). Diante do exposto, os objetivos deste trabalho são a utilização do processo de secagem por leito de jorro utilizando a maltodextrina como coadjuvante de secagem, bem como a caracterização dos parâmetros físicos e físico-químicos do produto obtido.

\section{MATERIAIS E MÉTODOS}

\subsection{Matéria-prima}

A polpa de umbu-cajá foi adquirida em um supermercado de Fortaleza-CE e levada para o laboratório de Controle de Qualidade e Secagem de Alimentos, onde foi armazenada em freezer a $-18^{\circ} \mathrm{C}$. Após o processo de descongelamento, sob refrigeração e realizado na embalagem original do produto, elaborou-se uma polpa formulada, composta de $500 \mathrm{~g}$ de polpa integral de umbu-cajá com adição de $15 \%$ e $30 \%$ do agente coadjuvante de secagem, maltodextrina DE20. Após completa dissolução e homogeneização, o material foi conduzido ao equipamento de secagem.

\subsection{Secagem em Leito de Jorro}

O secador utilizado nesta pesquisa é um equipamento que realiza tanto as operações de fluidização e leito de jorro, da labmaq do Brasil LTDA (modelo FBD 5.0). Possui peso total de $200 \mathrm{~kg}$, e altura total de $1,80 \mathrm{~m}$. As amostras foram desidratadas sob as seguintes condições de secagem: temperatura $\left(75^{\circ} \mathrm{C}\right)$; vazão de ar de secagem ou ar quente $\left(1,75 \mathrm{~m}^{3}\right.$ /min); velocidade de alimentação (4,0 $\mathrm{mL} / \mathrm{min})$; vazão de ar comprimido (30 L/min), pressão no bico atomizador 50 bar, velocidade do ar de secagem $(3,70 \mathrm{~m} / \mathrm{s})$ e peso do material inerte (400 g).

Foi utilizado um bico atomizador superior, onde a atomização é criada forçando o fluido através de um orifício. Este é um método eficiente de energia que também oferece uma distribuição mais estreita do tamanho das partículas. A vazão de ar pressurizado $(30 \mathrm{~L} / \mathrm{min})$ refere-se à atomização do fluido, pois esta ocorre quando a vazão do fluido encontra o ar pressurizado, e então, a amostra é seca através da vazão de ar quente do aparelho. As partículas inertes utilizadas são do tipo plástico polietileno, resistente ao calor. O tempo de atomização ocorre de 2 a 5 segundos. O tempo que em que o produto permanece no equipamento é de aproximadamente 2 horas. Desta maneira é estabelecido um padrão de circulação dessas partículas sólidas onde são formadas três regiões distintas: região do jorro, onde é formada quando as partículas são elevadas para cima em um fluxo concorrente ao do fluxo que passa a alta velocidade; região de fonte, quando as partículas provenientes da região de jorro desaceleram e mudam a direção radialmente caindo na região anular; região anular: após as partículas atingirem determinado nível retornam a base por uma região que fica entre 
o limite da região central e a parede da coluna conhecida como anular (EPSTEIN e GRACE 2011, p. 18).

Quando as partículas são transportadas verticalmente em fluxo concorrente ao do ar, o revestimento seco é reduzido a pó que é carregado pelo ar e coletado no ciclone acoplado ao secador e separado em um coletor de pó. Para evaporação da água nos produtos, o calor necessário é fornecido diretamente pelo ar quente que penetra no equipamento pela parte inferior, e indiretamente pelas partículas inertes aquecidas. Através desse funcionamento propicia um maior contato entre o fluído e as 23 partículas e, com isso, altas taxas de transferência de calor e massa (PASSOS e MUJUMDAR, 2000, p. 222).

\subsection{Caracterização físico-química da polpa de umbu-cajá em pó}

As análises físico-químicas foram realizadas no Laboratório de Controle de Qualidade e Secagem de Alimentos da Universidade Federal do Ceará e todas foram realizadas em triplicata. Os resultados foram avaliados pelo teste de diferença do tipo Tukey $(p<0,05)$. Os parâmetros analisados para a polpa de umbu-cajá foram: umidade em base úmida, atividade de água, $\mathrm{pH}$, acidez, sólidos solúveis, segundo metodologia descrita pelo Instituto Adolfo Lutz (2008), além da análise instrumental da cor. A análise de higroscopicidade foi determinada a partir da metodologia descrita por Goula e Adampoulos (2008). A cor foi determinada por um colorímetro Konica minolta Chroma meter CR-410 onde foram avaliados os seguintes parâmetros: coordenada L* (luminosidade), coordenada de cromaticidade a* (-a verde, +a vermelho) e a coordenada de cromaticidade $b^{*}$ (-b azul, $+b$ amarelo), além do Chroma $\left(\mathrm{C}^{*}\right)$ e ângulo Hue (H0*).

\section{RESULTADOS E DISCUSSÃO}

Dispõem-se na Tabela 1 os resultados das análises da polpa de umbu-cajá e dos pós obtidos por secagem em leito de jorro a partir da polpa, com adição do adjuvante de secagem maltodextrina a $15 \%$ e $30 \%$, respectivamente.

Tabela 1 - Parâmetros físico-químicos avaliados nos pós obtidos a partir da polpa de umbucajá por secagem em leito de jorro com adição do adjuvante de secagem maltodextrina a 15\% e $30 \%$.

\begin{tabular}{cccc}
\hline Parâmetro & Polpa & $\begin{array}{c}\text { Pó adicionado de } \\
15 \% \text { de } \\
\text { maltodextrina }\end{array}$ & $\begin{array}{c}\text { Pó adicionado de } \\
30 \% \text { de } \\
\text { maltodextrina }\end{array}$ \\
\hline Umidade (\%) & $89,94 \pm 0,66 \mathrm{a}$ & $1,00 \pm 0,02 \mathrm{~b}$ & $1,05 \pm 0,07 \mathrm{~b}$ \\
Atividade de água (Aw) & $0,98 \pm 0,00 \mathrm{a}$ & $0,23 \pm 0,04 \mathrm{~b}$ & $0,21 \pm 0,00 \mathrm{~b}$ \\
Higroscopicidade (\%) & - & $1,55 \pm 0,84 \mathrm{~b}$ & $9,92 \pm 1,30 \mathrm{a}$ \\
Sólidos solúveis $\left({ }^{\circ}\right.$ Brix) & $7,30 \pm 0,26 \mathrm{~b}$ & $81,60 \pm 0,05 \mathrm{a}$ & $85,00 \pm 0,10 \mathrm{~b}$ \\
pH & $2,46 \pm 0,09 \mathrm{ab}$ & $2,67 \pm 0,03 \mathrm{a}$ & $2,31 \pm 0,11 \mathrm{~b}$ \\
Acidez & $0,96 \pm 0,01 \mathrm{c}$ & $4,28 \pm 0,18 \mathrm{a}$ & $2,65 \pm 0,13 \mathrm{~b}$
\end{tabular}

Médias seguidas de desvio padrão. Letras iguais na mesma linha não diferem estatisticamente $(\mathrm{p}<0,05)$.

Em relação à análise do teor de umidade foi observado que a polpa apresentou valor de $89,94 \%$, equivalente ao encontrado por Mattietto et al.,(2010) ao analisar polpa de frutos 
provenientes de Belém-Pará. Com relação à umidade dos pós foi observado que não houve diferença significativa para a adição de 15 e $30 \%$ de maltodextrina, respectivamente. A redução do teor de umidade nos pós de polpa de fruta é notavelmente relacionada ao processo de desidratação, removendo grande parte da água nas polpas. Em relação ao parâmetro de atividade de água foi observado que a polpa apresentou um valor de 0,98. Segundo Abreu et al. (2003), frutas com valores de atividade de água superiores a 0,98 são mais suscetíveis à deterioração por bactérias, fungos e leveduras. Com relação aos pós foi observado que não houve diferença significativa entre os pós com 15 e 30\% de maltodextrina. Os valores encontrados estão dentro da faixa estabelecida para alimentos secos e estáveis do ponto devista microbiológico (atividade de água inferior a 0,6 e umidade menor que 25\%). Os valores de higroscopicidade mostraram que houve diferença estatística a um nível de $95 \%$ de confiança pelo teste de Tukey entre os valores de 1,55 e 9,92 dos pós. O agente coadjuvante utilizado teve influência sobre os valores dos pós obtidos. De acordo com Gea Niro (2003), as duas formulações podem ser classificadas como pós não higroscópicos por apresentarem valores inferiores a $10 \%$, sendo a formulação contendo $15 \%$ de maltodextrina a de menor percentual. Segundo Ross, 1995, uma alta higroscopicidade é indesejável para alimentos em pó, tendo em vista que promove aspecto pegajoso e dificulta a solubilidade do produto.

O teor de sólidos solúveis na polpa diferiu do padrão mínimo exigido pela legislação que estabelece um valor mínimo de $9,00^{\circ}$ Brix (BRASIL, 1999). Isto pode ocorrer devido ao fato de que o teor de sólidos solúveis pode variar com a quantidade de chuva durante a safra, fatores climáticos, variedade, solo, entre outros. Com relação ao teor de sólidos solúveis dos pós foi observado que não houve diferença significativa entre os valores de 81,60 e 85,0 dos pós com 15 e $30 \%$ de adição de maltodextrina, respectivamente. De acordo com Chitarra e Chitarra (2005) o teor de sólidos solúveis (SS) é utilizado como uma medida indireta do teor de açúcares presentes no alimento, ocorrendo um aumento à medida que há acúmulo de açúcares na fruta. As médias obtidas para $\mathrm{pH}$ e acidez das polpas de umbu-cajá encontram-se dentro dos Padrões de Identidade e Qualidade (PIQ) para o cajá estabelecidos pela legislação (Brasil, 1999), que estipulam os valores mínimos de $\mathrm{pH}(2,2)$, e acidez total $(0,9 \mathrm{~g} / 100 \mathrm{~g})$. Valores mais altos de $\mathrm{pH}$ (baixa acidez) são preferidos para o consumo in natura, porém constitui-se em problema para a indústria devido ao favorecimento das atividades enzimáticas e desenvolvimento de microrganismos. Em relação às médias obtidas para os parâmetros de pH e acidez total titulável dos pós de umbu-cajá, observou-se uma redução dos valores com o aumento da concentração de maltodextrina. A manutenção do $\mathrm{pH}$ baixo constitui um importante fator para melhor conservação do produto. A redução nos valores de acidez pode ser explicada pelo aumento na concentração de sólidos devido à adição do agente carreador.

Dispõe-se na Tabela 2 os resultados das análises de cor realizadas com a polpa in natura e da polpa de umbu-cajá em pó com concentração de 15 e 30\% de maltodextrina 
Tabela 2 - Parâmetros de cor avaliados nos pós obtidos a partir da polpa de umbu-cajá por secagem em leito de jorro com adição do adjuvante de secagem maltodextrina a $15 \%$ e $30 \%$.

\begin{tabular}{cccccc}
\hline Amostra/Parâmetro & $\mathrm{L}^{*}$ & $\mathrm{a}^{*}$ & $\mathrm{~b}^{*}$ & $\mathrm{C}^{*}$ & $\mathrm{H}$ (Hue) \\
\hline Polpa & $58,44 \pm$ & $6,50 \pm$ & $47,32 \pm 0$, & $47,63 \pm$ & $82,18 \pm$ \\
& $0,18 \mathrm{~b}$ & $0,15 \mathrm{a}$ & $28 \mathrm{a}$ & $0,50 \mathrm{a}$ & $0,14 \mathrm{c}$ \\
\hline & & & & & \\
Pó adicionado de $15 \%$ de & $58,00 \pm$ & $-2,45 \pm$ & $10,87 \pm 0$, & $11,14 \pm$ & $102,74 \pm$ \\
maltodextrina & $0,40 \mathrm{~b}$ & $0,10 \mathrm{~b}$ & $01 \mathrm{~b}$ & $0,03 \mathrm{~b}$ & $0,08 \mathrm{~b}$ \\
\hline & & & & & \\
Pó adicionado de 30\% de & $59,8 \pm$ & $-2,72 \pm$ & $10,74 \pm 0$, & $11,08 \pm$ & $104,19 \pm$ \\
maltodextrina & $0,15 \mathrm{a}$ & $0,01 \mathrm{~b}$ & $16 \mathrm{~b}$ & $0,16 \mathrm{~b}$ & $0,18 \mathrm{a}$ \\
\hline
\end{tabular}

Médias seguidas de desvio padrão. Letras iguais na mesma linha não diferem estatisticamente $(\mathrm{p}<0,05)$.

Em relação à cor do umbu-cajá no processo verifica-se, a partir dos parâmetros $\mathrm{a}^{*} \mathrm{e} \mathrm{b}^{*}$, que o componente amarelo, expresso pelo parâmetro $b^{*}$, é o de maior intensidade na coloração do umbu-cajá. Observa-se, ainda, que após o processo de secagem com adição da maltodextrina houve um decréscimo do parâmetro $b^{*}$, estas diferenças ao uso da maltodextrina que possui coloração branca e, desse modo, torna menos intensa a coloração dos pigmentos presentes na fruta. A incorporação do carreador proporcionou obtenção de amostra mais clara $\left(\mathrm{L}^{*}\right)$, sendo perceptível uma diminuição da luminosidade. Oliveira (2012) obteve valor de 58,41 para polpa de cajá liofilizada, verificando que durante o período de armazenamento do produto não houve diferenças significativas no valor de $\mathrm{L}^{*}$, afirmando que a maltodextrina contribuiu para evitar o escurecimento da amostra. Observou-se também um aumento em relação ao valor de Hue, para os pós, indicando coloração próxima ao amarelo.

\section{CONCLUSÃO}

O processo de secagem em leito de jorro em conjunto com a adição da maltodextrina como coadjuvante de secagem contribuiu para a conservação das características da polpa e aumento da vida útil do produto obtido, fatores que foram constatados a partir da redução no teor de umidade e Aw, manutenção do $\mathrm{pH}$ baixo e aumento no teor de sólidos solúveis totais do produto em pó.

\section{REFERÊNCIAS}

ABREU, M. C.; NUNES, I. F. S.; OLIVEIRA, M. M. A. Perfil microbiológico de polpas de frutas comercializadas em Teresina, PI. Higiene Alimentar, v. 17, n. 112, p. 78-81, 2003.

BRASIL. Agência Nacional de Vigilância Sanitária Resolução RDC n²72, 22 de setembro de 2005, que dispõe sobre o Regulamento Técnico para produtos vegetais, produtos de frutas e cogumelos comestíveis, Diário Oficial da República Federativa do Brasil, Brasília, DF,2005.

BRASIL. Ministério da Agricultura e do Abastecimento. Instrução Normativa ${ }^{\circ} 122$, de 10 de setembro de 1999. Diário Oficial da República Federativa do Brasil, Brasília, 13 de set. de 1999. Seção 1, p. 72-76 
BRASIL. Ministério da Agricultura e do Abastecimento. Instrução Normativa n. 1, de 07 de janeiro de 2000. Regulamento Técnico geral para Fixação dos Padrões de Identidade e Qualidade para polpa de fruta. Diário Oficial [da] República Federativa do Brasil, Brasília, 10 de janeiro de 2000, Seção 1, p. 54.

CHITARRA, M.I.F.; CHITARRA, A.B. Pós-colheita de frutas e hortaliças: fisiologia e manuseio. Lavras: UFLA, 2005.785p.

GEA Niro Research Laboratory. Analytical methods dry milk products. GEA Niro analytical methods 15 a. Soeborg, Denmark,2003.

GIACOMETTI, D.C. Recursos genéticos de fruteiras nativas do Brasil. In: SIMPÓSIO NACIONAL DE RECURSOS GENÉTICOS DE FRUTEIRAS NATIVAS, 1992, Cruz das Almas. Anais... Cruz das Almas: Embrapa-CNPMF, 1993. p.13-27.

GOULA, A. M.; ADAMOPOULOS, K. G. Water sorption isotherms and glass transition temperature of spray dried tomato pulp. Journal of Food Engineering, v. 85, p. 73-83, 2008.

GOULA, A.M; ADAMOPOULOS, K.G.A new technique for spray drying orange juiceconcentrate. Innovative Food Science and Emerging Technologies. v. 11, p. 342351, 2010.

VIANA, E.S. Embrapa realiza curso sobre processamento de frutas. Disponível em:. Acesso em: 29 fev. 2008.

IAL - INSTITUTO ADOLFO LUTZ. Normas analíticas do Instituto Adolfo Lutz: Métodos químicos e físicos para a análise de alimentos. 3. ed. São Paulo: Instituto Adolfo Lutz, 2008.

MATTIETTO, R. A.; LOPES, A. S.; MENEZES, H. C. Caracterização física e físico-química dos frutos da cajazeira (Spondias mombin L.) e de suas polpas obtidas por dois tipos de extrator. Braz. J. Food Technol., v. 13, n. 3, p. 156-164, 2010.

OLIVEIRA, G.S. Aplicação do processo de liofilização na obtenção de cajá em pó: avaliação das características físicas, físico-químicas e higroscópicas. 2012. Dissertação (Mestrado) - Departamento de Tecnologia de Alimentos, Universidade Federal do Ceará, Fortaleza CE.

OLIVEIRA, M. A. Avaliação da Influência de Adjuvantes de Secagem sobre as Propriedades de Suco de Caju Atomizado. Dissertação (Mestrado em Tecnologia de Alimentos) Departamento de Tecnologia de Alimentos, Universidade Federal do Ceará, Fortaleza, 2008.

PASSOS, M. L.; MUJUMDAR, A. S. Effect of cohesive forces on fluidized and spouted beds of wet particles. Powder Technology, v. 110, n. 3, p. 222-238, 2000. Disponível em:< www.elsevier.comrlocaterpowtec>. Acesso em: 10 de set. de 2013.

ROOS, Y. R. J. O.; Characterization of Food Polymers Using State Diagram. Journal of Food Engineering, v.24, p. 339-360, 1995.

SOARES, E. C.; Oliveira, G. S. F. de.; Maia, G. A.; Monteiro, J. C. S.; Silva Jr., A.; S. Filho, M. de S. de. Desidratação da polpa de acerola (Malpighia emarginata D.C.) pelo processo foam-mat . Ciência e Tecnologia de Alimentos, Campinas, v.21, n.2, 2001.

SILVA, R.N.G.; FIGUEIRÊDO, R. M. F.; QUEIROZ, A. J. M.; GALDINO, P. O. Armazenamento de umbu-cajá em pó. Rev.Ciência Rural, v.35, n.5, p.1179-1184, 2005a.

EPSTEIN, N.; GRACE, J. R. Introduction. In:

(Ed.). Spouted and Spout-Fluid Beds: Fundamentals and Applications. New York: Cambridge University press. 2011. p. 1-14. Disponível em:.<http://books.google.com.br/books/>. 